\title{
Development of high performance self-Lubricating spherical plain bearings and their friction and wear properties
}

\author{
NIU Rong Jun ${ }^{1,2, a}$, Zhang Jian $\mathrm{Hu}^{1, \mathrm{~b}}$, Ni Yan Guang ${ }^{2, \mathrm{c}}$ and Deng Si $\mathrm{Er}^{1}$ \\ ${ }^{1}$ School of Mechatronics Engineering, Henan University of Science and Technology, Luoyang \\ 471003, China \\ ${ }^{2}$ National United Engineering Laboratory for Advanced Bearing Tribology, Henan University of \\ Science and Technology, Luoyang 471132, China \\ aniurj@haust.edu.cn, ${ }^{\mathrm{b}}$ 1536260009@qq.com, ${ }^{\mathrm{c}}$ nyg321@126.com
}

\begin{abstract}
Keywords: spherical plain bearings; spherical contact; solid lubrication; friction and wear Abstract:To meet high frequency oscillating and light load conditions, a kind of self-lubricating spherical plain bearing used in the helicopter main rotor system is developed. The self-lubricating liner material is designed and woven with PTFE+Nomex fiber by three dimensional weaving process. The high-performance spherical plain bearings are manufactured by extrusion process. Then the high frequency oscillating friction and wear tester is used to verify the friction and wear properties of the fabric liner. The test results show that the self-lubricating spherical plain bearings developed can meet the designed performance requirements under given operating conditions. The friction coefficient and the friction temperature are at a lower level during the whole test process, and the liner is not worn out after the life assessment time.
\end{abstract}

\section{Introduction}

Self-lubricating spherical plain bearings with its excellent tribological properties are widely used in the key parts of modern aviation, aerospace, power and transportation equipment. Its stability, reliability and service life will directly affect the whole machine's performance, if there is sticking between the inner and outer rings or wear failure, which may bring disastrous consequences to the whole machine ${ }^{[1-2]}$. At present, with the development of the helicopter industry, it requires higher flexibility, long service life and high reliability. However, self-lubricating spherical plain bearings as the main connecting parts become the key to helicopter performance improvement. Therefore, the development of high performance self-lubricating spherical plain bearings is of great significance.

From the structural point of view, spherical plain bearings are spherical contacts instead of belonging to point contact or line contact of the traditional rolling bearings ${ }^{[3]}$; from the lining material point of view, the physical properties and mechanical properties of the self-lubricating liner attached to the ring surface differ greatly from the metal material, the material has a large dispersion ${ }^{[4-5]}$. The self-lubricating spherical plain bearings used for the helicopter main rotor must work for a long time under the condition of light load and high frequency oscillating. In this paper, a high-speed swinging alternating friction and wear test machine is applied to evaluate the friction and wear properties of a developed self-lubricating spherical plain bearings used on the main rotor of a helicopter, scanning electron microscope(SEM) is used to observe the morphology of the friction surface and analyze its wear mechanism, so as to provide a reference for the development of high-performance self-lubricating spherical plain bearings.

\section{Development of self-lubricating spherical plain bearings}

\section{Fabrication of fabric liner under high speed and light load conditions}

The main failure mode of self-lubricating spherical plain bearings is wear failure. In the process of swinging, the self-lubricating materials form a self-lubricating transfer film on the dual surface, in the stable wear stage, the dry friction action is converted into the self lubricating transfer film to liner materials, so as to reduce the shear force between the friction surfaces and the dry friction coefficient. 
This is the main reason for the low friction coefficient of the self-lubricating spherical plain bearings ${ }^{[6-9]}$. As the self-lubricating liner is constantly worn and extruded, the liner materials are worn out and failed finally. It can be seen from the failure process of the self lubricating spherical plain bearings that the bearing capacity, the limit speed, the friction coefficient and the wear resistance of the bearing directly depend on the performance of the self-lubricating liner material. The spherical plain bearings studied need to run for a long time under high frequency(nearly $15 \mathrm{~Hz}$ ) oscillating conditions. For this purpose, a more excellent self-lubricating material is needed to meet the requirements of this working condition. The self-lubricating liner material used is woven from PTFE+Nomex fiber by three dimensional weaving process, shown in Fig. 1. The fabric liner is mainly composed of matrix and reinforcing fibers, wherein the matrix part is a phenolic resin, the radial fiber bundle is woven by teflon fibers and nomex fibers, and the directional fiber bundle is made of nomex fibers. Nomex fiber is mainly used to improve the strength and bonding properties of the fabric liner material, while the PTFE fiber is mainly used to improve the material's friction and wear resistance, Fig. 1 shows the self-lubricating liner fiber structure.

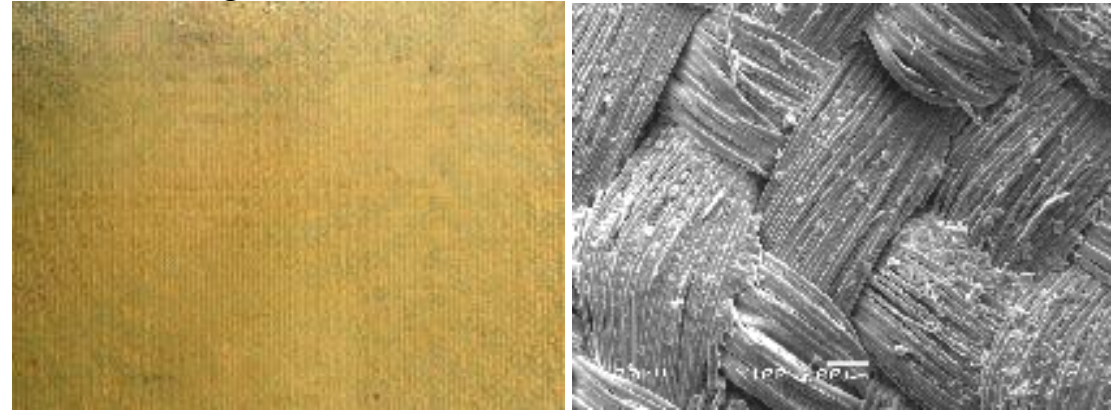

Figure 1 Self-lubricating liner material and fabric structure

\section{Manufacturing technology of the self-lubricating spherical plain bearings}
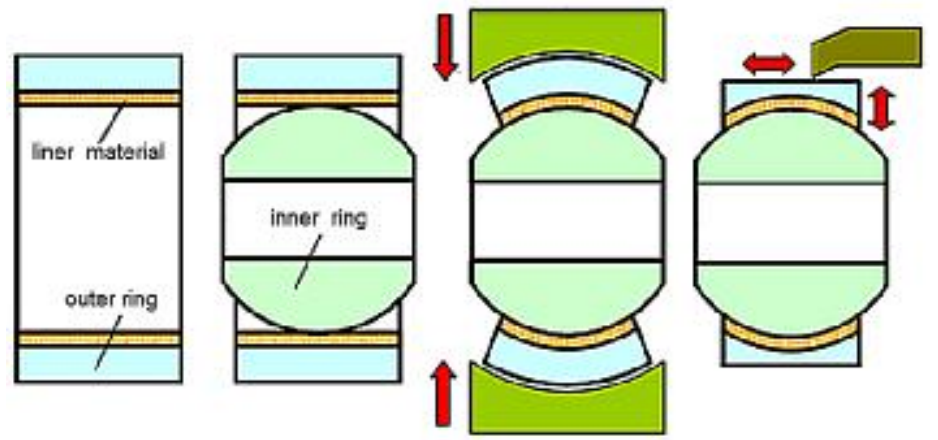

Figure 2 Manufacturing processes of the spherical plain bearing

In the case of high-performance fabric liner material to meet the performance test requirements, a lot of follow-up processes are needed to make the spherical plain bearing. After machining the inner and outer rings of the spherical plain bearing, the liner is bonded to the inner surface of the outer ring, and then the outer ring is fitted with the inner ring. Through the upper and lower molds and hydraulic loading, the outer ring is extruded and formed. Then the outer ring of the extrusion is turned and ground to meet the required dimensional accuracy requirements. Finally, the radial and axial bearing clearance are controlled through the clearance rolling process. The manufacturing process is shown in Fig.2.

Bonding and extrusion process are the key technology in the whole manufacturing process ${ }^{[10-11]}$. The bonding process requires a second curing process. The temperature and time in secondary curing process have a great influence on the curing quality, and it's also the key to ensure the smooth process of the subsequent extrusion. The adhesive surface of the outer ring needs to be sanding in order to ensure the high reliability of the bond quality. In the specific implementation of the extrusion process operation, the size of extrusion should be reasonably controlled and the parameters of the extrusion program should be selected reasonably. 


\section{High-performance self-lubricating spherical plain bearings test}

\section{Test equipment}

To verify the performance of the spherical plain bearing, the developed self-lubricating spherical plain bearing are tested by using the high frequency oscillating friction and wear life test machine. Fig. 3 is the physical diagram of the test, which mainly includes the hydraulic system, the high frequency oscillating system and the detection system. The loading system is loaded with hydraulic pressure to avoid the occurrence of eccentric compression and realize high load of the maximum positive pressure to $500 \mathrm{kN}$. In order to achieve high-frequency swing, the traditional crank connecting rod structure in the test machine is replaced by the high-frequency swing hydraulic cylinder, so that the highest swing frequency reaches $30 \mathrm{~Hz}$ and the maximum swing angle reaches $\pm 45^{\circ}$. The performance parameters of friction temperature, friction coefficient and wear depth during the test are collected in real time with high-sensitivity sensor and inputted into the computer for data processing.

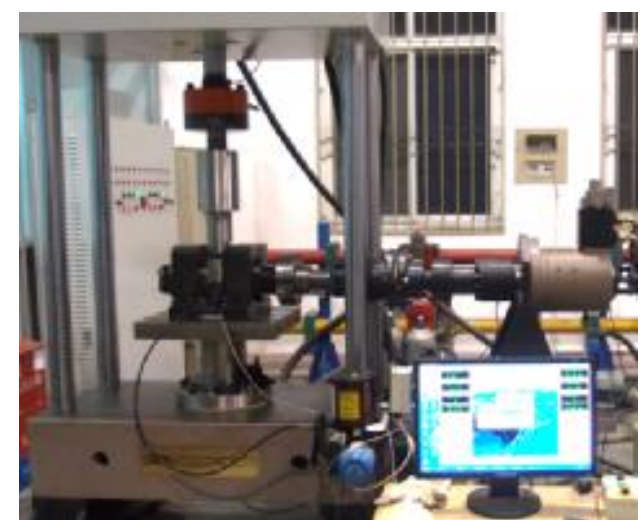

Figure 3 Friction and wear life test machine

\section{Performance test methods}

After the installation of the sample, 15 minutes of static loading is carried out firstly under the load of $15 \mathrm{MPa}(14.1 \mathrm{kN})$. Then the friction and wear life test is carried out under the condition of $15 \mathrm{MPa}$, $7.97 \mathrm{~Hz}$ and $\pm 8^{\circ}$ (equivalent to line speed $6.276 \mathrm{~m} / \mathrm{min}$ ), and the friction coefficient, friction temperature and deformation are detected online with the cycle times. Here the bearing temperature higher than $150^{\circ} \mathrm{C}$, or test time to reach 400 hours, or the liner material worn out are as the standard of wear failure and termination test.

\section{Test results and analysis}

\section{Friction and wear properties}

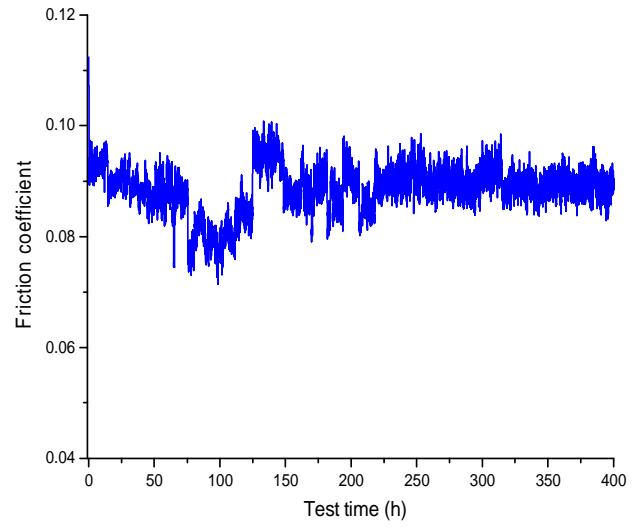

Figure 4 Friction coefficient with test time

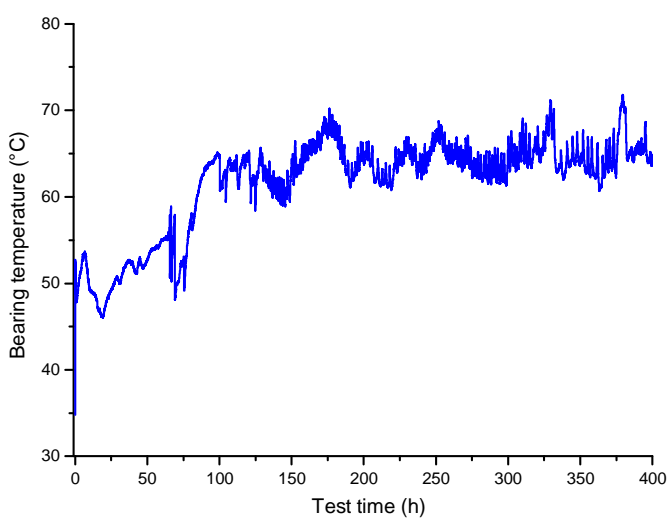

Figure 5 Temperature rise with test time 
Fig.4 shows the friction coefficient data curve of the bearing specimen with the test time . It can be seen that the friction coefficient is 0.112 at the initial stage of the test, and with the increase of the cycle times, the friction coefficient fluctuates in a small range in the test process, but it basically maintains at 0.09. This indicates that the friction pair of the self-lubricating liner material and chromed inner ring is easy to form transfer film on the contact surface under the condition of high frequency swing, so the friction coefficient can be kept at a low level. The self-lubricating transfer films maintain better supply and demand system in the whole life test process.

Fig. 5 shows the curve of the friction temperature of the bearing specimen with the test time. The effect of friction temperature rise has important effect on the wear life of the liner, excessive friction temperature will accelerate the peeling off and adhesive wear of the liner material, so the friction temperature must be maintained at a low level. From Fig.5, it can be seen that the friction temperature of the bearing specimens is at a low level of the maximum temperature up to 70 degree in the whole test time period, which helps to improve the self-lubricating performance of the liner and keep its friction coefficient and wear rate at a low level. Because of the poor thermal conductivity of the fabric liner, a large number of friction heat will accumulate in the middle of the liner under high frequency swing, and is not easy to conductive to the distribution of the fabric. Therefore, it is necessary to ensure good air mobility in practical application environment.

\section{Analysis of the mechanism of friction and wear}
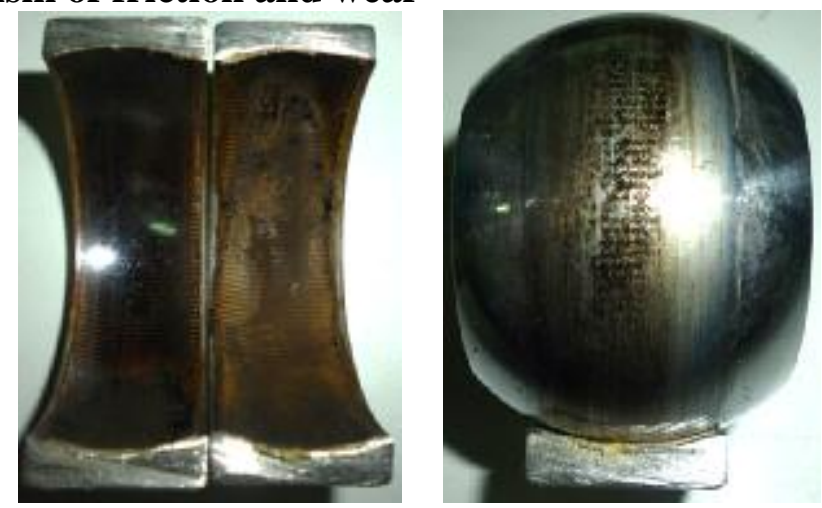

Figure 6 Section cutting view of the bearing test sample

In 400 hours life assessment time, the self-lubricating liner sticking to outer ring is still not worn out. The test results prove that the bearing meet the performance requirements of wear life. Then, the bearing specimen is cut, as shown in Fig.6. It can be seen that there is obvious carbonization in the bearing area of the liner, while the surface structure on the other half of the liner is better. However, the color of the fabric obviously becomes darkened because of the friction heat. A clear friction trace can be seen on the friction pair surface of the inner ring. Due to the shear effect, high-temperature carbonized self-lubricating transfer film adheres to the friction surface of the inner ring

The electron microscopy(SEM) is used to observe the surface topography of the friction pair and analyze the friction and wear mechanisms. The wear morphology of the liner is shown in Fig.9, it can be clearly seen that the texture of the fabric surface has been obviously worn, and the surface of the local lining texture has exposed and fatigued after the life test. While the whole texture of the liner is quite complete, and there is no appearance of the liner worn out.
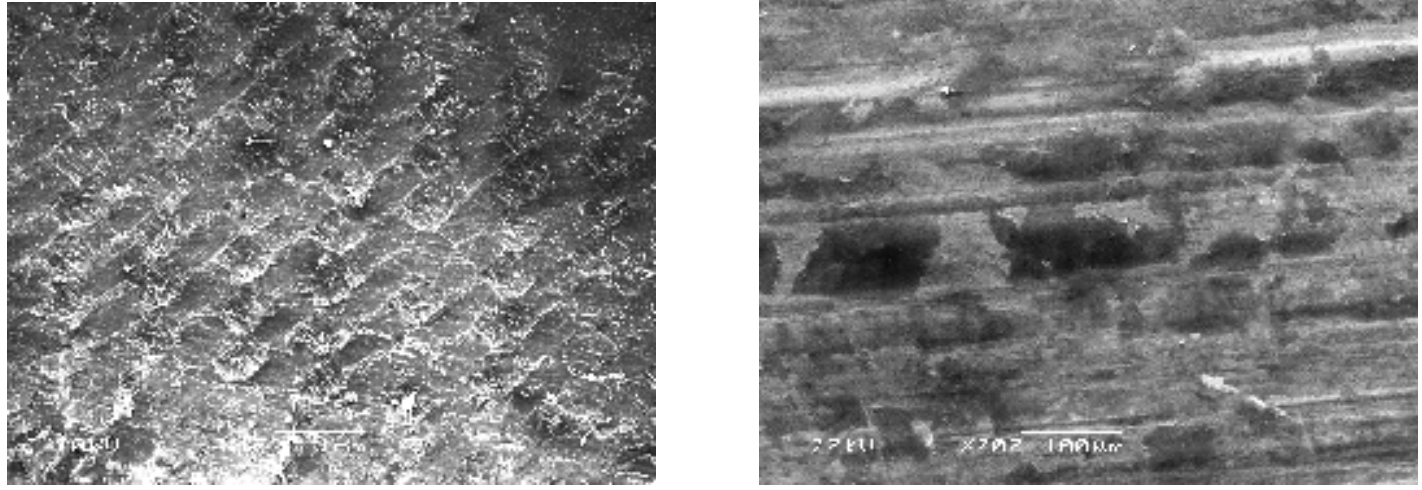
Figure 7 Micro topography of the liner Figure 8 Micro topography of the inner ring

Fig. 8 shows the friction surface micro-morphology of the inner ring, it can be seen that a self-lubricating transfer film with a certain thickness is formed on the friction surface of the inner ring. However, the thickness distributions of the transfer film are uneven and discontinuous, and there are clear plow effect produced in the transfer film, The possible reason is that the fatigue shedding debris influence the self-lubricating film on the inner ring surface through the ploughing wear form.

\section{Conclusion}

(1) To meet high frequency oscillating conditions of the spherical plain bearing, a self-lubricating liner material is designed and woven with PTFE+Nomex fiber by three dimensional weaving process.

(2) The manufacturing processes of the high-performance spherical plain bearing are introduced, in which the bonding and extrusion process are the key technology in the whole manufacturing process.The secondary curing process and parameters of the extrusion program should be selected reasonably.

(3) In the test process, the friction coefficient basically maintains at 0.09 , and the friction temperature is at a low level of the maximum temperature up to 70 degree. After 400 hours life assessment time, the self-lubricating liner sticking to outer ring is not worn out. The test results prove that the developed bearing meet the performance requirements.

\section{Acknowledgements}

This work was financially supported by Henan Natural Science Foundation Project (162300410086), the National United Engineering Laboratory for Advanced Bearing Tribology (201708), and Henan province science and technology key project (172102210254).

\section{Reference:}

[1] MA Jian, YANG Yulin, QI Xiaowen. Tribological Performances of Fabric self-lubricating liner with different weft densities under severe working conditions[J]. Indian Journal Fibre \& Textile Research, 2015, 40:293-300.

[2] LI Ruyah. The application of polytetrafluoroethene fabrics to spherical plain bearings[J]. Journal of Functional Materials, 2004, 35(S1):2221-2223.

[3] RBC. Spherical Plain Bearings[EB/OL]. http://www.rbcbearing.com, 2004.

[4] KIM B.C, LEE D.G. Endurance and Performance of a Composite Spherical Bearing[J]. Composite Structures[J]. 2009(87):71-79.

[5] RUSSELL Gay. Friction and Wear Behavior of Self-lubricating Bearing Liners[D]. Cardiff University, 2013.

[6] Jaydeep Khedkar, Ioan Neguleseu. Sliding wear behavior of PTFE composites[J]. Wear, 2002, 252:361-369.

[7] Xiang Dinghan, Pan Qinglin. Friction and wear behavior of polytertrafluorethylene fabric composite spherical bearing in swaying[J].Tribelogy, 2003, 23(1):72-75.

[8] Lu,M.Qiu,Y.C.Li,Numerical analysis of self-lubricating radial spherical plain bearings and investigations on fatigue damage mechanisms of the liner[J]. Tribol Int, 2016(96):97-108.

[9] M Qiu, Y C Li, L Chen, et al. Effects of rare earth treatment on tribological properties of self-lubricating spherical plain bearings[J]. Wear, 2013,305(1/2):274-279.

[10] B. C. Kim, D.G. Lee. Endurance and performance of a composite spherical bearing[J]. Compos Struct, 2009(87)1:71-79.

[11] SKF Corporation. SKF Spherical Plain Bearings and Rod Ends Catalogue. Goteborg, Sweden, 2011. 